\title{
Manipulation of Fe/Au Peroxidase-Like Activity for Development of a Nanocatalytic-Based Assay
}

\author{
Yazmin Bustami $^{12^{*}}$, Murray Moo-Young ${ }^{1}$ and William A. Anderson ${ }^{1}$ \\ ${ }^{1}$ Department of Chemical Engineering, University of Waterloo, Ontario, \\ N2L3G1, Canada \\ ${ }^{2}$ School of Biological Sciences, Universiti Sains Malaysia, 11800 USM \\ Pulau Pinang, Malaysia \\ *Corresponding author: ybustami@usm.my
}

Published online: 15 April 2017

To cite this article: Yazmin Bustami, Murray Moo-Young and William A. Anderson. (2017). Manipulation of $\mathrm{Fe} / \mathrm{Au}$ peroxidase-like activity for development of a nanocatalytic-based assay. Journal of Engineering Science, 13: 29-52, https://doi.org/10. 21315/jes2017.13.3.

To link to this article: https://doi.org/10.21315/jes2017.13.3

\begin{abstract}
Nanoparticles have been discovered to have intrinsic peroxidase-like catalytic activity that shows beneficial applications in a biosensor. The aim of this study is to investigate the synthesised Fe/Au nanoparticles' peroxidase-like activity and further evaluate them for development of a nanocatalytic-based assay specifically designed to detect 17B-estradiol in water. The peroxidase-like activity of the synthesised Fe/Au nanoparticles was optimised using the $\mathrm{H}_{2} \mathrm{O}_{2}$-ABTS system and was characterised using Michaelis-Menten kinetics. Then, the nanoparticles surface was functionalised with aptamers for specific conjugation with the target analyte, 17 -estradiol. The feasibility of this assay was tested at different concentration of aptamer-tagged Fe/Au nanoparticles and $17 \beta$-estradiol. Also, assessment of this assay was conducted with potentially interfering materials and spiked real tap water samples. Results obtained from absorbance data reveal that the Fe/Au-17ß-estradiol complex significantly hampered the peroxidase-like catalytic activity of the nanoparticles. The absorbance intensity declined drastically after aptamer-tagged nanoparticles (Fe/Au-fl-apt) "captured" the targets and formed nanoparticles-analytes complexes. This assay showed good accuracy and reproducibility for detection of $17 \beta$-estradiol concentration ranging from 3 to $272 \mathrm{ng} / \mathrm{L}$. Furthermore, the aptamers used in this study were very selective towards the target analyte and related compounds showed little to no interference. Thus, a simple, rapid and sensitive detection assay, specific for 17ß-estradiol was developed using a new detection strategy by manipulation of nanoparticles' peroxidase-like activity.
\end{abstract}

Keywords: $\mathrm{Fe} / \mathrm{Au}$ nanoparticles, peroxidase-like activity, nanocatalytic-based assay, detection of $17 \beta$-estradiol 


\section{INTRODUCTION}

Recently, many nanoparticles have been reported to show enzyme mimetic activity such as magnetite, ${ }^{1} \mathrm{Au}$ nanoparticles, ${ }^{2} \mathrm{Fe}_{3} \mathrm{O}_{4}-\mathrm{Au}^{3}$ and $\mathrm{Ag}_{3} \mathrm{PO}_{4}{ }^{4}$ These enzyme-like nanoparticles display a beneficial property as they could potentially replace peroxidase in various applications, including hydrogen peroxide dependent systems.

Besides the growing interest in nanoparticles' catalytic property, nanoparticles have long been known for their excellent ability to conjugate with biomolecules such as enzymes, DNAzymes, antibodies and aptamers. These biomolecules can be immobilised on the modified nanoparticle surfaces by direct conjugation to the surface of some nanoparticles and to surface-bound stabilising ligands or coatings, either directly or using small cross-linking molecules and other intermediaries. ${ }^{5}$ Aptamers are short synthetic oligonucleotides that could be chemically synthesised for any targets and show many advantages, for examples easy to modify, high stability and cost effective. ${ }^{6,7}$

Analytical assays that utilise a hydrogen peroxide dependent system by catalysing the oxidation of certain substrates have been extensively used for numerous applications. This analytical assay has become a powerful detection tool especially in immunoassay studies. Recently, replacement of horseradish peroxidase with nanoparticles as a peroxidase mimetic has demonstrated improvement in biosensors. Zhang's group presented work with $\gamma-\mathrm{Fe}_{2} \mathrm{O}_{3}$ nanoparticles modified by Prussian blue (PBMNPs) that were further conjugated with staphylococcal protein A (SPA) and showed a potential application in biodetection. Here, the PBMNPs served as an inexpensive horseradish peroxidase, HRP. ${ }^{8}$ A recent study by Liu et al. ${ }^{9}$ reported that the incorporation of casein on magnetic nanoparticles helped to improve the affinity towards both $\mathrm{H}_{2} \mathrm{O}_{2}$ and $3,3^{\prime}, 5,5^{\prime}$ - tetramethylbenzidine (TMB) thus resulting in a simple, inexpensive, highly sensitive and selective method for glucose detection.

While prior work has demonstrated the capability of nanoparticles to conjugate with the target analytes and has utilised nanoparticles' peroxidase-like activity for an analytical assay, we observed that a similar strategy could be adapted for development of a nanocatalytic-based assay. It has been reported that peroxidase-like activity of iron oxide nanoparticles is dependent on the surface attributes of the nanoparticles. ${ }^{10}$ Therefore, in this study we report on a detection strategy formulated by the nanoparticles capability to conjugate with analytes and then the nanoparticles-analytes catalytic activity was evaluated using a hydrogen peroxide dependent system. We envisaged that the conjugation of target analytes to the $\mathrm{Fe} / \mathrm{Au}$ nanoparticles would hinder the peroxidase activity resulting in an assay response that was inversely proportional to the analyte concentration. This 
is based on the fact that the formation of this complex would create a gap with substrate molecules and lower the nanoparticles catalytic activity by reducing the affinity of nanoparticles for substrate molecules.

To evaluate the feasibility of this assay, the synthesised nanoalloy, $\mathrm{Fe} / \mathrm{Au}$ nanoparticles were initially assessed for their peroxidase-like activity using the hydrogen peroxide dependent system, $\mathrm{H}_{2} \mathrm{O}_{2}$-ABTS. A specifically designed aptamer was attached to the $\mathrm{Fe} / \mathrm{Au}$ nanoparticles to confer specific conjugation abilities for the target analyte, 17 $\beta$-estradiol. It is known as an endocrine disrupting chemical (EDCs) that has the greatest estrogenic activity. ${ }^{11}$ When $17 \beta-$ estradiol was successfully "captured" by aptamer-tagged nanoparticles and formed $\mathrm{Fe} / \mathrm{Au}-17 \beta$-estradiol complex, the catalytic activity of this complex was measured using the hydrogen peroxide dependent system.

This is the first work reported, to our knowledge, to use this approach for development of such a detection assay. Hence, it is hoped that this study would initiate a comprehensive research exploration of nanoparticles' peroxidase-like activity in nanosensor systems and further develop a simple, reliable and sensitive detection assay.

\section{MATERIALS AND METHODS}

\subsection{Chemicals}

Chemical reagents used in this experiment were ferrous sulfate heptahydrate $\left(\mathrm{FeSO}_{4} .7 \mathrm{H}_{2}\right.$, ReagentPlus $\left.{ }^{\circledR},>99 \%\right)$, hydrogen tetrachloro-aurate (III) (HAuCl4.3H2O, $\geq 99.9 \%)$, sodium hydroxide ( $\mathrm{NaOH}$, ACS Reagent, $\geq$ $97 \%)$, trisodium citrate $\left(\mathrm{Na}_{3} \mathrm{C}_{6} \mathrm{H}_{5} \mathrm{O}_{7}\right.$, anhydrous, $\geq 98 \%$, GC), nitric acid $\left(\mathrm{HNO}_{3}\right.$, ACS Reagent $70 \%$ ) diluted to $65 \%$, phosphate buffered saline (PBS) buffer (tablet), Tween 20 (viscous liquid), 2,2'-azino-bis(3-ethylbenzthiazoline-6sulfonic acid) diammonium salt (ABTS, $10 \mathrm{mg} /$ tablet), $30 \% \mathrm{H}_{2} \mathrm{O}_{2}$, PBS buffer (tablet), Tween 20 (viscous liquid), sodium acetate anhydrous (NaAc), MES buffer ( $\geq 99.5 \%), 17 \beta$-estradiol (98\%), estriol ( $\geq 97 \%)$, nonylphenol (99.8\%) and carbaryl (99.8\%). These chemical reagents were purchased from Sigma Aldrich. Thiolated aptamer (SH-apt) was adapted from Wang, Wang and Dong ${ }^{12}$ with slight modification and was synthesised at Alpha DNA (Montreal, Quebec) and the probe aptamer (fl-apt) was adapted from Kim et al. ${ }^{13}$ with slight modification and was synthesised from Eurofins MWG Operon LLC (Hunstville, AL). All reagents were analytical grade and were used as received without further purification. 


\subsection{Preparation of Fe/Au Nanoparticles}

The formation of $\mathrm{Fe} / \mathrm{Au}$ nanoparticles is based on electrostatic interaction between positively charge $\gamma-\mathrm{Fe}_{2} \mathrm{O}_{3}$ as in Nurdin et al. ${ }^{14}$ and negatively charge citrate-capped AuNPs. Initially, they were synthesised separately. $\gamma-\mathrm{Fe}_{2} \mathrm{O}_{3}$ were synthesised using a reverse co-precipitation method adapted from Mahmed et al. ${ }^{15}$ with slight modification and then were treated with $\mathrm{HNO}_{3}(6 \mathrm{~mol})$. AuNPs were synthesised using the Turkevish method by mixing $500 \mu \mathrm{L} \mathrm{HAuCl}_{4} .3 \mathrm{H}_{2} \mathrm{O}$ $(10 \mathrm{mM})$ in a solution containing $300 \mu \mathrm{L} \mathrm{Na}{ }_{3} \mathrm{C}_{6} \mathrm{H}_{5} \mathrm{O}_{7}(100 \mathrm{mM})$ and $10 \mathrm{~mL}$ deionised water. Then, $12 \mathrm{mg} / \mathrm{mL}$ of $\gamma-\mathrm{Fe}_{2} \mathrm{O}_{3}$ were mixed with $2.5 \mathrm{~mL}$ citratecapped AuNPs for $1 \mathrm{~h}$. Then, the nanoparticles were separated by a permanent magnet overnight. The separated $\mathrm{Fe} / \mathrm{Au}$ nanoparticles were stabilised with 3.5 $\mathrm{mL}$ of PBS-T (10 mM, pH 4) by vigorous mixing for $1 \mathrm{~h}$. Subsequently, the solution was centrifuged for $10 \mathrm{~min}$ at $6.5 \times 1000 \mathrm{rpm}$ and the $\mathrm{Fe} / \mathrm{Au}$ nanoparticles were separated using a permanent magnet and washed several times with PBS-T and stored at $4^{\circ} \mathrm{C}$ until use.

\subsection{Measurement of Fe/Au Peroxidase-Like Activity}

The prepared $\mathrm{Fe} / \mathrm{Au}$ nanoparticles weighed to approximately $50 \mathrm{mg}$ and were added into $1 \mathrm{~mL}$ PBS buffer $(10 \mathrm{mM}, \mathrm{pH} 4)$. The extent of reaction was indicated by a green colour development and was measured by absorbance at 414 $\mathrm{nm}$ based on the presence of the oxidised ABTS $\left(\mathrm{ABTS}_{\mathrm{ox}}\right)$ in the solution, using microplate reader (Multiskan Ascent, Labsystems). To calculate the amount of absorption that is contributed by the $\mathrm{Fe} / \mathrm{Au}$ catalytic reaction, the obtained absorbance needed to be subtracted from the control absorbance. The catalytic reaction by $\mathrm{Fe} / \mathrm{Au}$ is as follows:

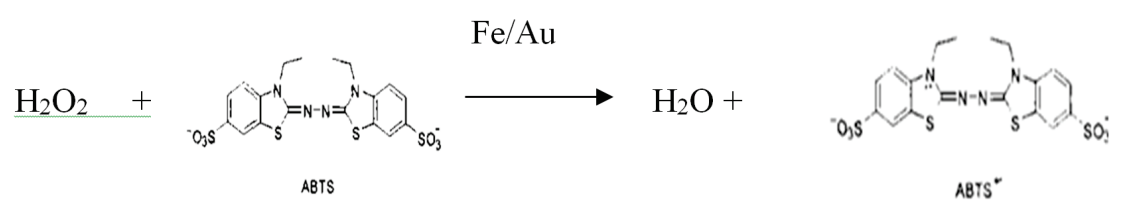

\subsection{Steady-State Kinetic Analysis}

The kinetic analysis of $\mathrm{Fe} / \mathrm{Au}$ and $\gamma-\mathrm{Fe}_{2} \mathrm{O}_{3}$ nanoparticles with $\mathrm{ABTS}$ as the substrate was performed by adding $10 \mu \mathrm{L}$ of nanoparticles aliquot, $10 \mu \mathrm{L}$ of $\mathrm{H}_{2} \mathrm{O}_{2}(100 \mathrm{mM})$ and different concentrations $(0.9,1.8,3.6$ and $4.5 \mathrm{mM})$ of ABTS reagent. For kinetic analysis with $\mathrm{H}_{2} \mathrm{O}_{2}$ as the substrate, $10 \mu \mathrm{L}$ of nanoparticles aliquot, $30 \mu \mathrm{L}$ of ABTS $(18.2 \mathrm{mM})$ and different concentrations $(0.5,1.5,2.5$ and $5.0 \mathrm{mM}$ ) of $\mathrm{H}_{2} \mathrm{O}_{2}$ were used. Both kinetic analyses were performed in $165 \mu \mathrm{L}$ 
reaction buffer $(10 \mathrm{~mm} \mathrm{NaAc}, \mathrm{pH} 5)$. The green colour developed as the reactions proceeded was monitored kinetically in a 96-well microplate at room temperature for $300 \mathrm{sec}$ with $60 \mathrm{sec}$ of time interval. The Michaelis-Menten constant was estimated based on a Hanes-Woolf plot:

$$
\frac{[S]}{v}=\frac{[S]}{V_{\max }}+\frac{K_{m}}{V_{\max }}
$$

where $v$ is the initial velocity, $V_{\max }$ is the maximal reaction velocity, $[S]$ is the concentration of substrate and $K_{m}$ is Michaelis constant for the particular enzyme being investigated.

\subsection{Development of Nanocatalytic-Based Assay}

\subsubsection{Surface functionalisation with aptamer}

$\mathrm{Fe} / \mathrm{Au}$ nanoparticles were weighed to approximately $50 \mathrm{mg}$ and were added to $1 \mathrm{~mL}$ MES buffer $(10 \mathrm{mM}$, pH 4). Subsequently, $5 \mu \mathrm{mol}$ of the thiolated aptamer (SH-apt) was added to the solution and this was incubated by mixing at room temperature for $1 \mathrm{~h}$. To remove the unbound $\mathrm{SH}$-apt, the solution was centrifuged for $5 \mathrm{~min}$ and was washed twice with PBS-T, $\mathrm{pH} 4$ and was further separated using a permanent magnet. $1 \mathrm{~mL}$ MES buffer, $\mathrm{pH} 7$ was added to the $\mathrm{Fe} / \mathrm{Au}-\mathrm{SH}$-apt nanoparticles. The next step of this strategy was to attach the probe aptamer (fl-apt) to the Fe/Au-SH-apt nanoparticles, where $5 \mu \mathrm{mol}$ of fl-apt was added to the solution. The interaction was allowed at room temperature for $1 \mathrm{~h}$. To remove the unbound fl-apt, the solution was centrifuged for $10 \mathrm{~min}$ and was washed twice with PBS-T, $\mathrm{pH} 4$ and was separated using permanent magnet. Finally, $1 \mathrm{~mL}$ PBS buffer, $\mathrm{pH} 4$ was added to the aptamer-tagged nanoparticles (Fe/Au-fl apt) and stored at $4^{\circ} \mathrm{C}$ until use. The presence of bound aptamers on the nanoparticles surface was evaluated using a UV-VIS spectrophotometer (Diode Array spectrophotometer, HP) based on the presence of fluorescent molecules, cyanine dyes (Cy5.5). Two types of aptamers used in this study are $\mathrm{SH}-\mathrm{apt}$ ( $\mathrm{SH}-$ C6-TCTCTTGGACCC) and fl-apt (AGAGAACCTGGG-GCT-TCC-AGCTTA-TTG-AAT-TAC-ACG-CAG-AGG-GTA-GCG-GCT-CTG-CGCATTCAA-TTG-CTG-CGC-GCT-GAA-GCG-CGG-AAG-C-(Cy5.5)).

\subsubsection{Assessment of nanocatalytic-based assay}

$10 \mu \mathrm{L}$ of the prepared Fe/Au-fl-apt nanoparticles (approximately $50 \mathrm{mg}$ ) was incubated with $100 \mu \mathrm{L}$ of $17 \beta$-estradiol (100 nmol) and $890 \mu \mathrm{L}$ PBS buffer $(10 \mathrm{mM}, \mathrm{pH} 4)$ at room temperature for $1 \mathrm{~h}$ to allow Fe/Au-17ß-estradiol complex formation. To remove the unbound 17ß-estradiol, the solution was 
centrifuged for 10 min and was washed twice with PBS-T, $\mathrm{pH}$ 4, and was further separated using a permanent magnet. Then, the nanoparticles-analytes catalytic activity was measured by adding $50 \mu \mathrm{L}$ of $\mathrm{Fe} / \mathrm{Au}-17 \beta$-estradiol aliquot, $10 \mu \mathrm{L}$ of $\mathrm{H}_{2} \mathrm{O}_{2}(100 \mathrm{mM}), 30 \mu \mathrm{L}$ of ABTS reagent $(18.2 \mathrm{mM})$, and $110 \mu \mathrm{L}$ reaction buffer $(10 \mathrm{mM}$ NaAc, $\mathrm{pH}$ 5) in 96-wells microplate. The absorbance signal at $414 \mathrm{~nm}$ was measured using the microplate reader after $5 \mathrm{~min}$ of interaction. High absorbance intensity indicated that a strong catalytic activity was present.

Further assessment was done by testing a serial dilution of $17 \beta$-estradiol $(0.01, \quad 0.1, \quad 1.0$ and $10 \mathrm{nmol})$ at different $\mathrm{Fe} / \mathrm{Au}-\mathrm{fl}-\mathrm{apt}$ nanoparticles concentrations $(33,17$ and $2.5 \mathrm{mg} / \mathrm{mL})$ in PBS buffer $(10 \mathrm{mM}, \mathrm{pH} 4)$ with total volume of $1 \mathrm{~mL}$. To remove the unbound $17 \beta$-estradiol, the solution was centrifuged for $10 \mathrm{~min}$ and was washed twice with PBS-T, $\mathrm{pH}$ 4, and was further separated using a permanent magnet. Then, the nanoparticles-analytes catalytic activity was measured as discuss previously.

In this study, the experimental assay was measured in triplicate $(n=3)$ for inter- assay and two assays run $(n=2)$ for determination of intra-assay variability. To assess the selectivity of this assay, a cross-reactivity study was conducted with potentially interfering materials such as estriol, nonylphenol (4NNP) and carbaryl and was evaluated at $100 \mathrm{nmol}$ concentrations for each EDCs. To further test this assay in real water sample, different concentration of $17 \beta$-estradiol $(0.1,1$ and $10 \mathrm{nmol})$ was added into filtered tap water (F) and nonfiltered tap water (NF). Then, $10 \mu \mathrm{L}$ prepared Fe/Au-fl-apt nanoparticles (approximately $50 \mathrm{mg}$ ) was added into the contaminant solution with total volume of $1 \mathrm{~mL}$. The detection was conducted at room temperature for $1 \mathrm{~h}$. To remove the unbound $17 \beta$-estradiol, the solution was centrifuged for $10 \mathrm{~min}$ and was washed twice with PBS-T, $\mathrm{pH} 4$, and was further separated using a permanent magnet. Then, the nanoparticles-analytes catalytic activity was measured and detection efficiency was calculated as follows:

$$
\left(\mathrm{A}_{0}-\mathrm{A}\right) / \mathrm{A}_{0}
$$

whereas $\mathrm{A}_{0}$ and $\mathrm{A}$ are absorbance intensity at $414 \mathrm{~nm}$ before and after various concentration of $17 \beta$-estradiol are added in tap water samples.

\subsubsection{Characterisation}

For morphology and heterostructural analysis, the nanoparticle samples were sent to the Canadian Centre for Electron Microscopy (CCEM), McMaster University, where high-resolution transmission electron microscopy (HRTEM, JEOL) was used at an accelerating voltage of $200 \mathrm{kV}$, and the Energy Dispersive $\mathrm{X}$-Ray Analysis (EDX) technique was used to identify the elemental composition 
of the materials. Zeta potential was employed using a Malvern Zetasizer to obtain information on the nanoparticles surface charge.

\section{RESULTS AND DISCUSSION}

\subsection{Analysis of Fe/Au Peroxidase-Like Activity}

$\mathrm{Fe} / \mathrm{Au}$ nanoparticles are prepared by a strong electrostatic interaction between $\gamma-\mathrm{Fe}_{2} \mathrm{O}_{3}$ and AuNPs that subsequently formed a metastable heterogeneous structure as characterised using TEM and EDX (S1). Due to the fact that both nanoparticles $\left(\gamma-\mathrm{Fe}_{2} \mathrm{O}_{3}\right.$ and AuNPs) exhibit a good peroxidase-like activity, it is of interest to investigate the catalytic activity of the synthesised $\mathrm{Fe} / \mathrm{Au}$ nanoparticles. The catalysis performance of the synthesised nanoparticles was examined using ABTS, a non-carcinogenic chromogenic substrate and is oxidised in the presence of peroxidase and $\mathrm{H}_{2} \mathrm{O}_{2}$ to a green reaction product with maximum absorbance at approximately $414 \mathrm{~nm}$.

The optimum $\mathrm{pH}$ value for nanoparticles' catalytic activity was found at $\mathrm{pH} 5$ and a linear absorbance of Fe/Au concentration (0.995) was obtained (S2). We also observed that increase of nanoparticles concentration also contribute to nanoparticles aggregation and we can speculate that due to the increase of nanoparticles-substrate interaction that lead to surface modification, the nanoparticle tends to aggregate since $\mathrm{Fe} / \mathrm{Au}$ shows metastable structure.

\subsection{Steady-State Kinetic Analysis}

The steady-state reaction rates at different concentrations of substrate and co-substrate (ABTS and $\mathrm{H}_{2} \mathrm{O}_{2}$ ) were obtained by calculating the slopes of initial absorbance changes with time. The reaction was determined in $10 \mathrm{mM}$ NaAc buffer, pH 5 at room temperature for $300 \mathrm{sec}$. Absorbance data were backcalculated to concentration by the Beer-Lambert Law using a molar absorption coefficient of $36,000 \mathrm{~mol}^{-1} \mathrm{~cm}^{-1}$ for ABTS-derived oxidation products at 414 $\mathrm{nm} .{ }^{16}$ As a comparison, the steady state kinetics for $\gamma$ - $\mathrm{Fe}_{2} \mathrm{O}_{3}$ nanoparticles were also examined to investigate the surface modification impact on catalytic activity.

The reaction catalysed by $\mathrm{Fe} / \mathrm{Au}$ and $\gamma-\mathrm{Fe}_{2} \mathrm{O}_{3}$ nanoparticles displayed Michaelis-Menten kinetics (S3). The Michaelis constant $\left(K_{m}\right)$ and maximal reaction velocity $\left(V_{\max }\right)$ were obtained from the slope and intercept of the extrapolated straight line with the horizontal axis in the Hanes-Woolf plot (S4). A high $K_{m}$ value represents a weak affinity whereas a low $K_{m}$ value suggests high affinity. ${ }^{17} K_{m}$ value of $\mathrm{Fe} / \mathrm{Au}$ with $\mathrm{H}_{2} \mathrm{O}_{2}$ as the substrate was significantly lower than $\gamma-\mathrm{Fe}_{2} \mathrm{O}_{3}$ (Table 1) shows that $\mathrm{Fe} / \mathrm{Au}$ nanoparticles have a strong affinity 
towards $\mathrm{H}_{2} \mathrm{O}_{2}$. In addition, the corresponding $K_{m}$ values of the $\mathrm{Fe} / \mathrm{Au}$ nanoparticles also indicate that the catalytic reaction can reach the maximum rate at a lower concentration of $\mathrm{H}_{2} \mathrm{O}_{2}$. According to Voinov et al., ${ }^{17} \mathrm{Fe}_{3} \mathrm{O}_{4}$ nanoparticles were significantly more effective in producing hydroxyl radicals $(\mathrm{OH})$ than the $\gamma-\mathrm{Fe}_{2} \mathrm{O}_{3}$ nanoparticles at the same ratio of the nanoparticle total surface and reaction volume. The peroxidase-like activity mostly originates from ferric ions which have a low rate constant and is thus a rate-limited reaction process. $^{8}$

Study conducted by Sun et al. $^{3}$ demonstrated that $\mathrm{Fe}_{3} \mathrm{O}_{4}-\mathrm{Au}$ nanocomposites exhibited better catalytic activity than pure $\mathrm{Fe}_{3} \mathrm{O}_{4}$ resulting from the specific electronic structure at the nanoparticles interfaces. They proposed that the AuNPs changed the electron structure at the interface, which may accelerate the electron transfer. Moreover, the partial electron transfer from $\mathrm{Fe}_{3} \mathrm{O}_{4}$ to $\mathrm{Au}$ facilitates $\mathrm{H}_{2} \mathrm{O}_{2}$ adsorption and activation. Hence, it is most likely the synthesised $\gamma-\mathrm{Fe}_{2} \mathrm{O}_{3}$ catalytic activity in this study was enhanced upon surface modification with AuNPs as proven by the strong affinity of $\mathrm{Fe} / \mathrm{Au}$ nanoparticles towards $\mathrm{H}_{2} \mathrm{O}_{2}$.

Conversely, the $K_{m}$ value for $\mathrm{Fe} / \mathrm{Au}$ nanoparticles with $\mathrm{ABTS}$ as the substrate was slightly higher than $\gamma-\mathrm{Fe}_{2} \mathrm{O}_{3}$, suggesting that the $\mathrm{Fe} / \mathrm{Au}$ nanoparticles had a slightly lower affinity for ABTS. The plausible reason for this phenomenon is due to the difference in charges present on the $\mathrm{Fe} / \mathrm{Au}$ and $\gamma$ $\mathrm{Fe}_{2} \mathrm{O}_{3}$ nanoparticles' surface. Results obtained from zeta potential measurements showed that the $\gamma-\mathrm{Fe}_{2} \mathrm{O}_{3}$ nanoparticles have a positive surface charge $(+17.80$ $\mathrm{mV})$ while $\mathrm{Fe} / \mathrm{Au}$ nanoparticles have a negative surface charge $(-24.70 \mathrm{mV})$ (S5). It is known that ABTS contains two negatively charged sulfonic groups, thus, exhibiting higher affinity toward a positively charged nanoparticles surface. ${ }^{10}$ However, the effect of charge difference was relatively small because of the slight difference in $K_{m}$ values, and suggested that the surface modification by $\mathrm{Au}$ deposition help to enhance the interaction between nanoparticles and ABTS.

Therefore, the intrinsic peroxidase-like activity of $\mathrm{Fe} / \mathrm{Au}$ nanoparticles is largely influenced by surface modification. From this information, we could utilised the nanoparticles surface modification flexibility and manipulate the catalytic property to develop an analytical assay. Development of the detection assay is further discussed in the next subsection. 
Table 1: Comparison of the kinetic parameters of $\gamma-\mathrm{Fe}_{2} \mathrm{O}_{3}$ and $\mathrm{Fe} / \mathrm{Au}$ nanoparticles.

\begin{tabular}{lccc}
\hline Nanoparticles & Substrate & $K_{m}(\mathrm{mM})$ & $V_{\max }\left(\mathrm{mols}^{-1}\right)$ \\
\hline$\gamma-\mathrm{Fe}_{2} \mathrm{O}_{3}$ & $\mathrm{H}_{2} \mathrm{O}_{2}$ & 0.137 & $2.892 \times 10^{-7}$ \\
& $\mathrm{ABTS}$ & 0.674 & $9.400 \times 10^{-8}$ \\
$\mathrm{Fe} / \mathrm{Au}$ & $\mathrm{H}_{2} \mathrm{O}_{2}$ & 0.021 & $5.935 \times 10^{-8}$ \\
& $\mathrm{ABTS}$ & 1.019 & $9.226 \times 10^{-8}$ \\
\hline
\end{tabular}

\subsection{Development of Nanocatalytic-Based Assay}

\subsubsection{Analysis of aptamer-mediated conjugation}

The probe aptamer that contained a fluorescent dye-labeled $17 \beta$-estradiol (fl-apt) was easily attached at the $\mathrm{SH}$-apt complementary site by interaction between the nucleobases. After the nanoparticles were successfully functionalised with the probe aptamer, Fe/Au-fl-apt would be able to "capture" the $17 \beta$-estradiol molecules in solution by conjugation at site-specific sequence, and subsequently form $\mathrm{Fe} / \mathrm{Au}-17 \beta$-estradiol complexes (S6).

The SH-apt would covalently attach to the Fe/Au nanoparticles based on the Au-SH chemisorption interaction where the sulfur atom of a thiol contributes a lone pair of electrons to the empty orbitals of $\mathrm{Au}$ atoms at an interface. ${ }^{5}$ Another advantage of introducing a thiolated-aptamer is to avoid aptamer desorption from the nanoparticle's surface and loss the nanoparticle functionality. On the other hand, the attachment of the fl-apt would facilitate the conjugation process between nanoparticles and $17 \beta$-estradiol molecules due to the presence of $17 \beta$-estradiol site-specific sequence. The attachment of the fl-apt to thiolatedtagged nanoparticles can be determined using cyanine dye, Cy5.5. This dye excites at $675 \mathrm{~nm}$ and emits at $695 \mathrm{~nm} .{ }^{18}$ The fluorescence emission intensity at $695 \mathrm{~nm}$ was measured from the visible light absorption spectrum. We could observe a broad band ranging from 600 to $700 \mathrm{~nm}$ suggesting that the fl-apt was successfully attached to the thiolated-tagged nanoparticles and no obvious peak was observed for $\mathrm{Fe} / \mathrm{Au}$ nanoparticles (S7). The possible reason for its low absorbance intensity might be due to the quenching effect of $\mathrm{Fe} / \mathrm{Au}$ nanoparticles, as both $\mathrm{Fe}$ and $\mathrm{Au}$ nanoparticles can be efficient fluorescence quenchers as demonstrated by many analytical analysis studies. ${ }^{19,20}$

\subsubsection{Detection of 17ß-estradiol}

A simple nanocatalytic-based assay to detect $17 \beta$-estradiol was devised as illustrated in Figure 1. In general, this assay requires two simple steps, immobilisation and catalytic reaction process. The immobilisation process is based on the conjugation of aptamer-tagged nanoparticles with $17 \beta$-estradiol. The 
bound $17 \beta$-estradiol formed a complex at the nanoparticle surface and this was easily separated from the solution using a permanent magnet. Then, the catalytic property of $\mathrm{Fe} / \mathrm{Au}-17 \beta$-estradiol was measured using the $\mathrm{H}_{2} \mathrm{O}_{2}$-ABTS system in a 96-well microplate. The absorbance signal was measured at $414 \mathrm{~nm}$ as an indicator that oxidised ABTS was present in the solution.

From result in Figure 2, we can observe that a slight difference could be found after $\mathrm{Fe} / \mathrm{Au}$ nanoparticles were functionalised with probe aptamer $(\mathrm{Fe} / \mathrm{Au}-$ fl-apt). The effect of surface functionalisation with probe aptamer is negligible due to its low impact on the nanoparticles catalytic activity. Inversely, the absorbance intensity was significantly decreased after nanoparticles-analytes complex was formed. Low absorbance intensity indicates that weak catalytic activity is involved. Thus, it clearly shows that the peroxidase activity of $\mathrm{Fe} / \mathrm{Au}$ nanoparticles is disrupted or hindered by $\mathrm{Fe} / \mathrm{Au}-17 \beta$-estradiol complex formation. This forms the basis of the assay, where a reduced signal should be proportional to an increase in $17 \beta$-estradiol concentration, and vice-versa.

To further evaluate the feasibility of this assay, a serial dilution of $17 \beta-$ estradiol $(0.01,0.1,1.0$ and $10 \mathrm{nmol})$ was tested at different concentrations of aptamer-tagged nanoparticles $(33,17$ and $2.5 \mathrm{mg} / \mathrm{mL}$ ). As expected, the absorbance intensity was inversely proportional to the $17 \beta$-estradiol concentrations (Figure 3). Therefore, we could suggest that steric hindrance effects are most likely contributing to the disruption of nanoparticles catalytic activity. According to the literature, for small-molecules targets like 17ßestradiol, aptamers often form a cage surrounding the ligand. ${ }^{21,22}$ Thus, it is speculated that when aptamer-tagged nanoparticles "captured" 17 $\beta$-estradiol, the aptamer became folded and formed a cage surrounding the target. Assuming many cages were formed at the $\mathrm{Fe} / \mathrm{Au}$ nanoparticles surface resulting in molecular crowding, its effect on the nanoparticles' catalytic activity is substantial. A study by Pitulice et al. ${ }^{23}$ revealed that the volume occupied by the crowding agent has a significant impact on the rate of ABTS reaction by $\mathrm{H}_{2} \mathrm{O}_{2}$ and catalysed by HRP. The $V_{\max }$ and $K_{m}$ of the Michaelis-Menten plot decay along with the growth of obstacle concentration.

It is known that interaction between the nanoparticles and substrate is important to ensure the catalytic process can occur, similar to enzyme-substrate interaction principals. The intermolecular steric hindrance considerably affects the catalytic activity of nanoparticles because the active centre (catalytic site) is less accessible to the substrate molecules. Since the substrates are unable to move into close proximity, interaction between nanoparticles and substrate molecules is interrupted causing weak apparent catalytic activity. 

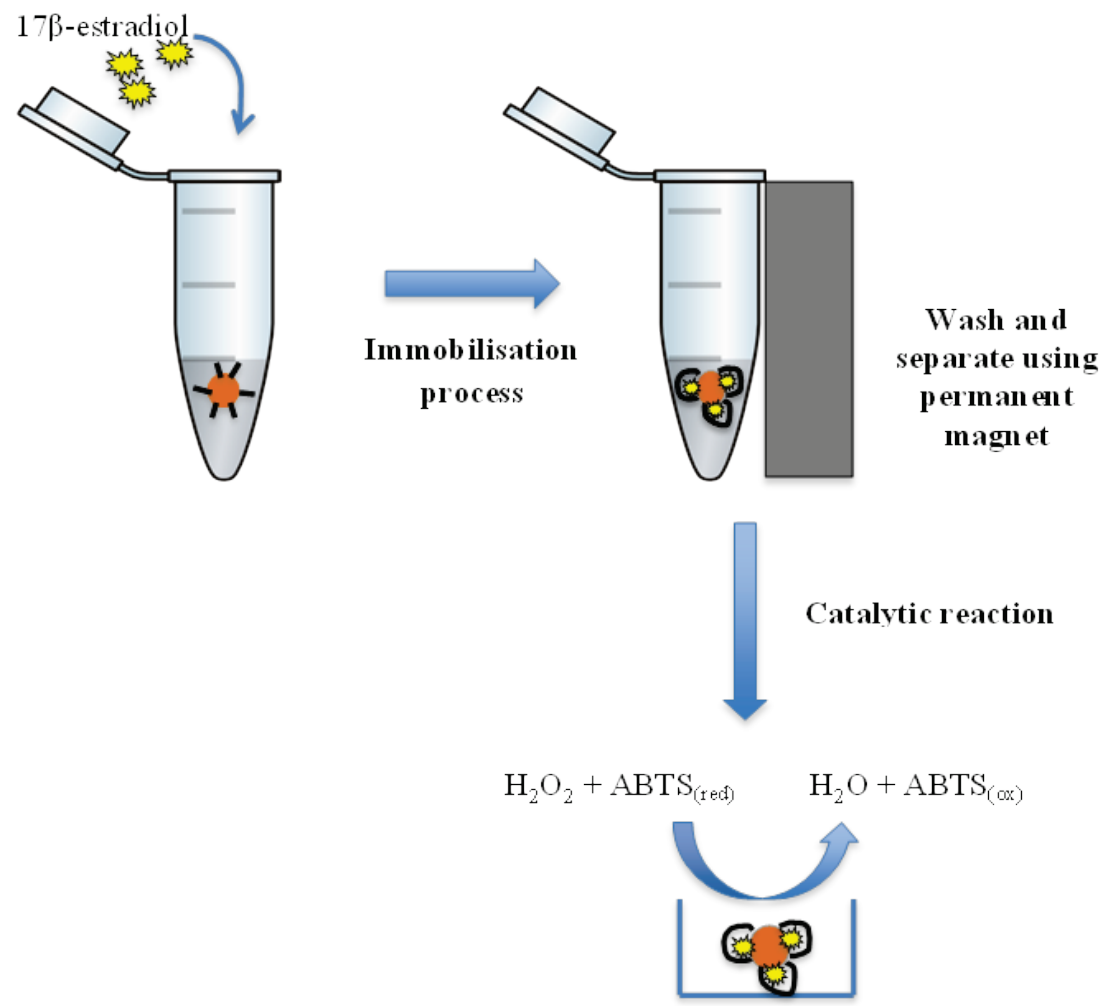

Measurement at $414 \mathrm{~nm}$

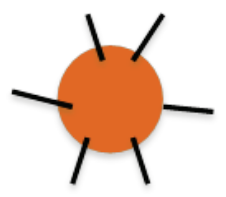

$\mathrm{Fe} / \mathrm{Au}-\mathrm{fl}-\mathrm{apt}$

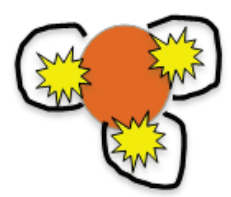

Fe/Au-17ß-estradiol

Figure 1: Illustration of the detection strategy for a nanocatalytic-based assay that consists of two main steps i.e. an immobilisation process and a catalytic reaction process, measured at $414 \mathrm{~nm}$ wavelength for $5 \mathrm{~min}$ of reaction. 


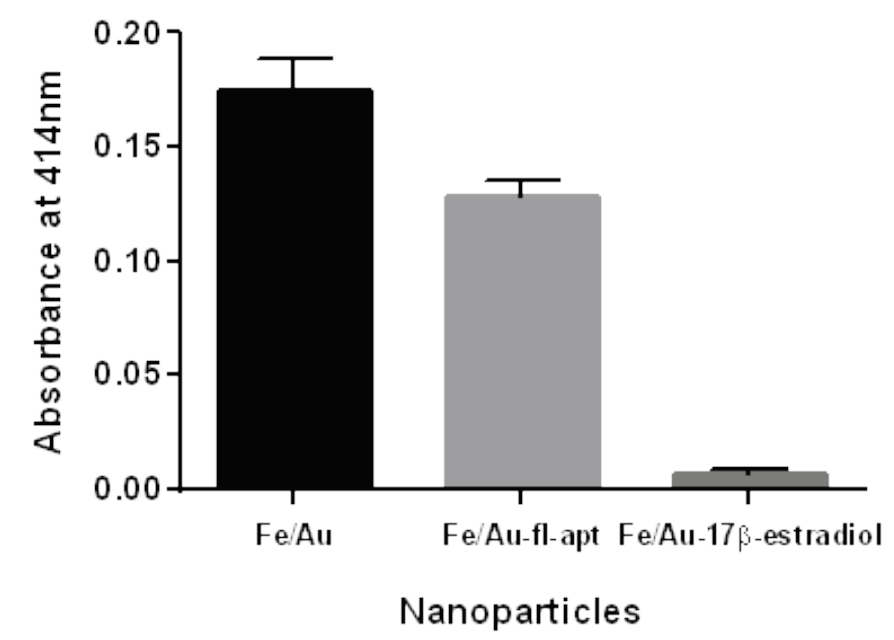

Figure 2: Absorbance intensity at $414 \mathrm{~nm}$ for unmodified $(\mathrm{Fe} / \mathrm{Au})$ and modified nanoparticles (Fe/Au-fl-apt; Fe/Au-17 $\beta$-estradiol) with each nanoparticles concentration approximately $12.5 \mathrm{mg} / \mathrm{mL}$ (error bars represent standard deviation [S.D.] of the absorbance mean).

At low aptamer-tagged nanoparticles concentrations $(2.5 \mathrm{mg} / \mathrm{mL})$, a linear correlation coefficient was obtained, suggesting a better sensitivity for $17 \beta$-estradiol detection. Further evaluation for batch-to-batch reproducibility was conducted (S8). A low CV (\%) can be observed for 17 $\beta$-estradiol concentration ( 0.01 to $1 \mathrm{nmol}$ ) indicating that the developed assay could be used repeatedly, and further revealed the possibility of batch preparation. A study by Atkinson ${ }^{24}$ reported that $17 \beta$-estradiol was found at maximum concentrations in raw sewage (Ottawa and Cornwall, Ontario, Canada) at $66.9 \mathrm{ng} / \mathrm{L}$. For this assay, the detection limit is ranging from 3 to $272 \mathrm{ng} / \mathrm{L}$ based on the calculation of $17 \beta-$ estradiol molecular weight $(272.4 \mathrm{~g} / \mathrm{mol})$. Therefore, this assay shows a practical use for detection of $17 \beta$-estradiol in environment particularly in wastewater. 


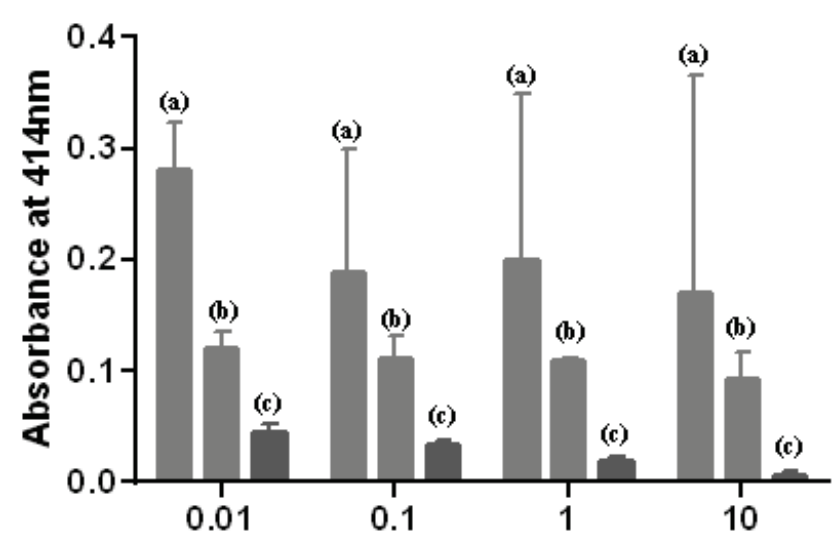

\section{[17 $\beta$-estradiol] (nM)}

Figure 3: Serial dilution of $17 \beta$-estradiol at different aptamer-tagged nanoparticles concentration, (a) 33, (b) 17 and (c) $2.5 \mathrm{mg} / \mathrm{mL}$ (error bars represent S.D. of the absorbance mean).

\subsubsection{Specificity test}

To determine the specificity of the probe aptamer used in this study, several related endocrine disrupting chemicals (EDCs) such as carbaryl, 4NNP and estriol were studied by incubation with the $\mathrm{Fe} / \mathrm{Au}$ nanoparticles. Then, the nanocatalytic-based assay was measured for each EDCs sample. As shown in Figure 4, the results from this assay show a slight absorbance difference between the blank control (Fe/Au-fl-apt) and ones containing other EDCs. In contrast, the absorbance declined substantially when $17 \beta$-estradiol was incubated with the nanoparticles, indicating a good selectivity of this assay. Therefore, the nanocatalytic-based assay using the probe aptamer attached on $\mathrm{Fe} / \mathrm{Au}$ nanoparticles surface could specifically detect $17 \beta$-estradiol. 


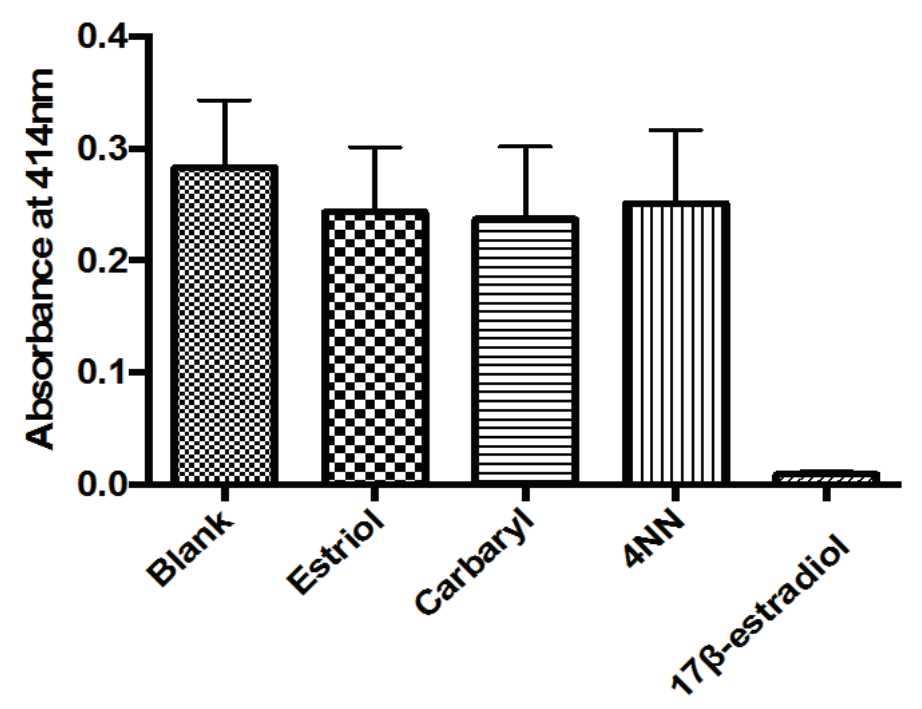

Figure 4: Cross-reactivity study with estriol, carbaryl and nonylphenol (4NNP). All the samples were evaluated at $100 \mathrm{nmol}$ of each EDCs with approximately 12.5 $\mathrm{mg} / \mathrm{mL}$ of $\mathrm{Fe} / \mathrm{Au}-\mathrm{fl}-\mathrm{apt}$ nanoparticles concentration (error bars represent S.D. of the absorbance mean).

\subsubsection{Tap water test}

Based on this preliminary study to evaluate the detection efficiency in real water samples, the detection efficiency of Fe/Au-fl-apt nanoparticles show considerably good responses towards $17 \beta$-estradiol in filtered tap water $(\mathrm{F})$ compared to non-filtered tap water (NF). The plausible reason is because the presence of other particles in NF that possibly interfere significantly the $\mathrm{Fe} / \mathrm{Au}$ nanoparticles catalytic activity. Surprisingly, high detection efficiency of $17 \beta-$ estradiol at concentration $10 \mathrm{nmol}$ was obtained for NF (Figure 5). Thus, this preliminary testing in tap water provides a good starting point for detection of $17 \beta$-estradiol in real water samples using Fe/Au-fl-apt nanoparticles. 


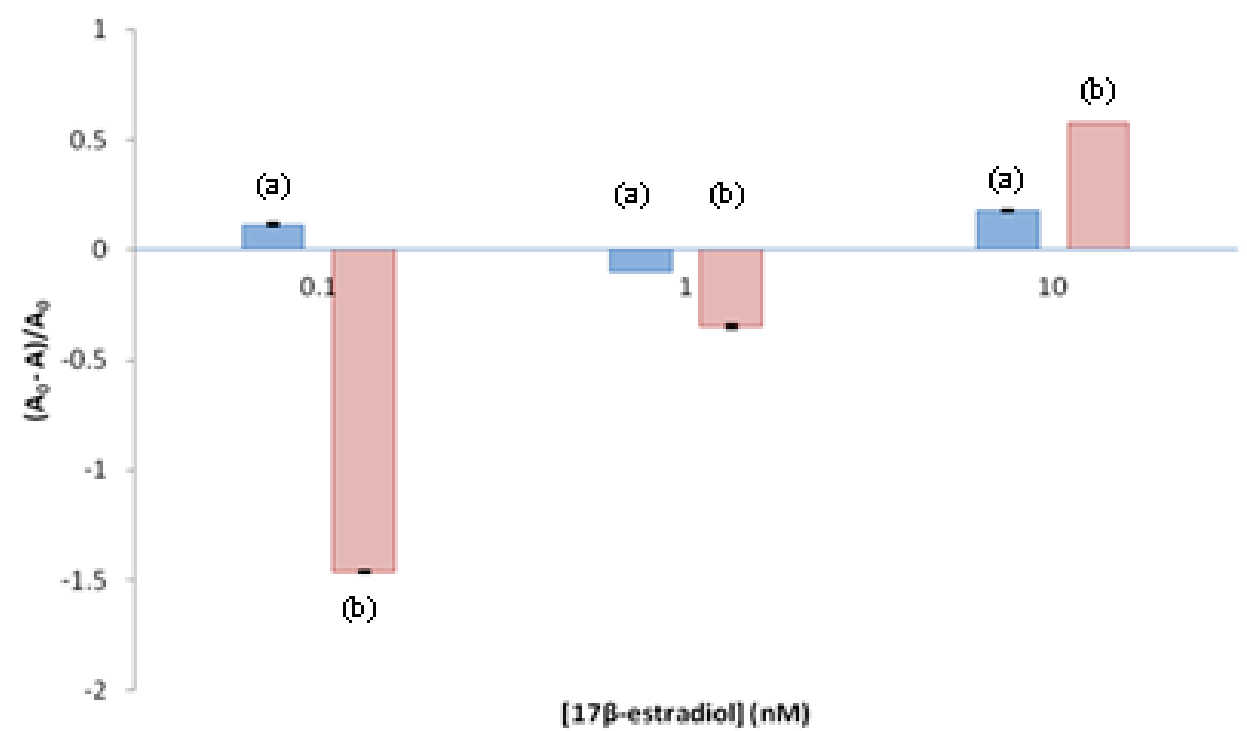

Figure 5: Detection efficiency of Fe/Au-fl-apt nanoparticles with various concentration of $17 \beta$-estradiol in tap water samples. Two types of tap water samples were tested, (a) NF and (b) F. All the samples were evaluated with approximately $12.5 \mathrm{mg} / \mathrm{mL}$ of Fe/Au-fl-apt nanoparticles concentration (error bars represent S.D. of the absorbance mean).

\section{CONCLUSION}

In summary, we investigated the synthesised $\mathrm{Fe} / \mathrm{Au}$ nanoparticles' intrinsic peroxidase-like activity and the potential manipulation of this interesting property for development of a nanocatalytic-based assay. A catalytic reaction by the $\mathrm{Fe} / \mathrm{Au}$ nanoparticles for the oxidation of ABTS by $\mathrm{H}_{2} \mathrm{O}_{2}$ showed a typical Michaelis-Menten kinetic form and exhibited a good catalytic efficiency. We also functionalised the nanoparticles by attachment of a specific aptamer to "capture" a target analyte, $17 \beta$-estradiol that would form a nanoparticles-analytes complex. The formation of this complex significantly influenced and decreased the nanoparticles' catalytic activity as shown by drastic declines in the absorbance intensity. We suggest that steric effects might be a plausible reason for this phenomenon since the active centre, which is the catalytic site, is less accessible to the substrate molecules once the target analyte has complexed with the nanoparticle. We also suggest that $17 \beta$-estradiol concentrations ranging between 3 to $272 \mathrm{ng} / \mathrm{L}$ are detected with this assay with good accuracy and reproducibility. However, a study of optimised sensing conditions needs to be done, in order to improve the assay performance, as this is our first attempt to investigate the practicality of this assay. 
Our study provides a new way of utilisation of the nanoparticles' peroxidase-like activity for development of a simple, rapid and sensitive detection assay that appears to specifically detect $17 \beta$-estradiol in aqueous solution.

\section{ACKNOWLEDGEMENTS}

Yazmin Bustami had been awarded financial support from Universiti Sains Malaysia and Ministry of Higher Education Malaysia.

\section{REFERENCES}

1. Liang, M. et al. (2013). Fe3O4 magnetic nanoparticle peroxidase mimetic-based colorimetric assay for the rapid detection of organophosphorus pesticide and nerve agent. Anal. Chem., 85(1), 308312, https://doi.org/10.1021/ac302781r.

2. Jv, Y., Li, B. \& Cao, R. (2010). Positively-charged gold nanoparticles as peroxidase mimic and their application in hydrogen peroxidase and glucose detection. Chem. Commun., 46, 8017-8019, https://doi.org/10.1039/c0cc02698k.

3. Sun, H. et al. (2013) Synthesis of $\mathrm{Fe}_{3} \mathrm{O}_{4}-\mathrm{Au}$ nanocomposites with enhanced peroxidase-like activity. Eur. J. Inorg. Chem., 2013(1): 109114, https://doi.org/10.1002/ejic.201201159.

4. Liu, Y. et al. (2014). Peroxidase-like catalytic activity of $\mathrm{Ag}_{3} \mathrm{PO}_{4}$ nanocrystals prepared by a colloidal route. PLOS ONE, 9(10), 1-7, https://doi.org/10.1371/journal.pone.0109158.

5. Sapsford, K. E. et al. (2013). Functionalizing nanoparticles with biological molecules: Developing chemistries that facilitate nanotechnology. Chem. Rev., 113(3), 1904-2074, https://doi.org/10. 1021/cr300143v.

6. Yildirim N. et al. (2012). Aptamer-based optical biosensor for rapid and sensitive detection of 17beta-estradiol in water samples. Environ. Sci. Technol., 46(6), 3288-3294, https://doi.org/10.1021/es203624w.

7. Sun, H. \& Zu, Y. (2015). A highlight of recent advances in aptamer technology and its application. Molecules, 20(7), 11959-11980, https://doi.org/10.3390/molecules200711959.

8. Zhang, X. Q. et al. (2010). Prussian blue modified iron oxide magnetic nanoparticles and their high peroxidase-like activity. J. Matter. Chem., 20, 5110-5116, https://doi.org/10.1039/c0jm00174k. 
9. Liu, Y. et al. (2014). An efficient colorimetric biosensor for glucose based on peroxidase-like protein- $\mathrm{Fe}_{3} \mathrm{O}_{4}$ and glucose oxidase nanocomposites. Biosens. Bioelectron., 52, 391-396, https://dx.doi.org/10.1016/j.bios.2013.09.020.

10. Yu, F. et al. (2009). The artificial peroxidase activity of magnetic iron oxide nanoparticles and its application to glucose detection. Biomater., 30(27), 4716-4722, https://doi.org/10.1016/j.biomaterials.2009.05.005.

11. Liu, J. et al. (2014). Highly sensitive colorimetric detection of $17 \beta-$ estradiol using split DNA aptamers immobilized on unmodified gold nanoparticles. Sci. Rep., 4, 1-6, https://doi.org/10.1038/srep07571.

12. Wang, J., Wang, F. \& Dong, S. (2009). Methylene blue as an indicator for sensitive electrochemical detection of adenosine based on aptamer switch. J. of Electro. Chem., 626(1-2), 1-5, https://doi.org/10.1016/j. jelechem.2008.08.008.

13. Kim, Y. S. et al. (2007). Electrochemical detection of $17 \beta$-estradiol using DNA aptamer immobilized gold electrode chip. Biosens. Bioelectron., 22(11), 2525-2531, https://doi.org/10.1016/j.bios.2006.10.004.

14. Nurdin, I. et al. (2014). Effect of nitric acid concentrations on synthesis and stability of maghemite nanoparticles suspension. The Sci. World J., 589479, 1-6, https://doi.org/10.1155/2014/589479.

15. Mahmed, N. et al. (2011). Room temperature synthesis of magnetite (Fe3-8O4) nanoparticles by a simple reverse co-precipitation method. IOP Conf. Series: Materials Sci. and Eng., 18, 1-4.

16. Liu, Y. et al. (2014). Negatively charged gold nanoparticles as an intrinsic peroxidase mimic and their applications in the oxidation of dopamine. J. Mater. Sci., 49(20), 7143-7150, https://doi.org/10.1007/ s10853-014-8422-x.

17. Voinov, M. A. et al. (2011). Surface-mediated production of hydroxyl radicals as a mechanism of iron oxide nanoparticle biotoxicity. J. Am. Chem. Soc., 133(1), 35-41, https://doi.org/10.1021/ja104683w.

18. Umezawa, K. et al. (2009). Bright, color tunable fluorescent dyes in the Vis/NIR region: Establishment of new "tailor made" multicolor fluorophores based on borondipyrromethene. Chem. Eur. J., 15(5), 1096-1106, https://doi.org/10.1002/chem.200801906.

19. Raikar, U. S. et al. (2011). Fluorescence quenching using plasmonic gold nanoparticles. Opt. Comm., 284(19), 4761-4765, https://doi.org/10. 1016/j.optcom.2011.05.038.

20. Kang, K. A. et al. (2011). Fluorescence manipulation by gold nanoparticles: From complete quenching to extensive enhancement. $J$. Nanobiotechnol., 9(16), 1-13, https://doi.org/10.1186/1477-3155-9-16.

21. Long, S. B. et al. (2008). Crystal structure of an RNA aptamer bound to thrombin. $R N A, 14(12), 2504-2512$, https://doi.org/10.1261/rna.1239308. 
22. Huang, D. B. et al. (2003). Crystal structure of NF-кB (p50)2 complexed to a high-affinity RNA aptamer. Proc. of the Nat. Acad. of Sci. of the USA, 100(16), 9268-9273, https://doi.org/10.1073/pnas.1632011100.

23. Pitulice, L. et al. (2013). Influence of macromolecular crowding on the oxidation of ABTS by hydrogen peroxide catalyzed by HRP. J. Biocatal. Biotransformation., 2(1), http://doi.org/10.4172/2324-9099.1000107.

24. Atkinson, S. K. et al. (2012). The occurance of steroidal estrogens in south-eastern Ontario Wastewater treatment plants. Sci. of the Tot. Env., 430, 119-125, https://doi.org/10.1016/j.scitotenv.2012.04.069.

\section{APPENDIX}

\section{Supplementary Materials 1 (S1)}

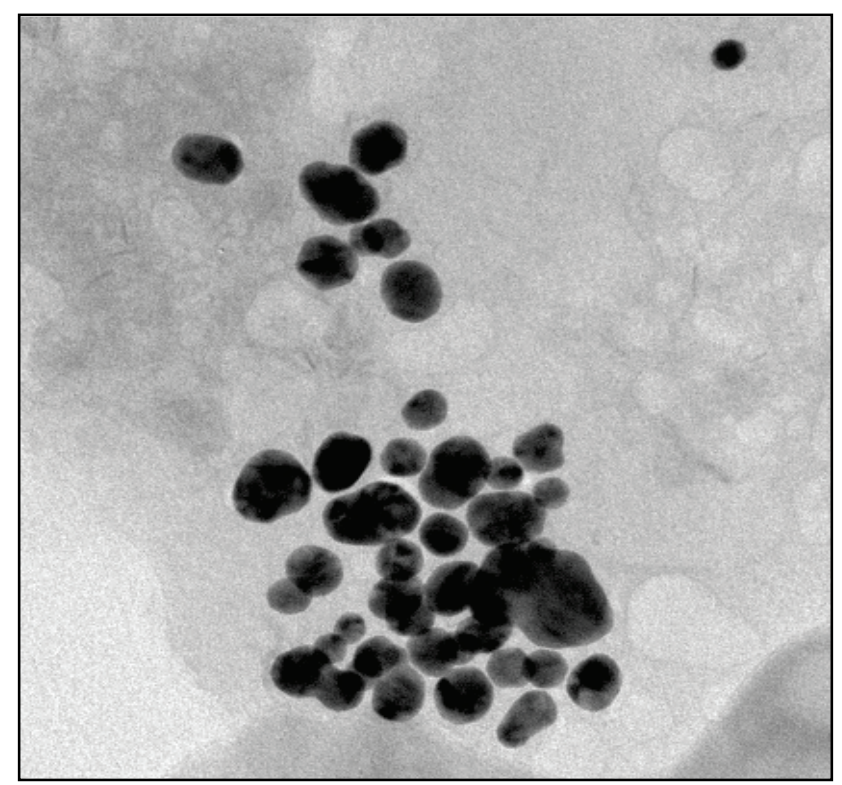

TEM image of metastable Fe/ Au nanoparticles. 


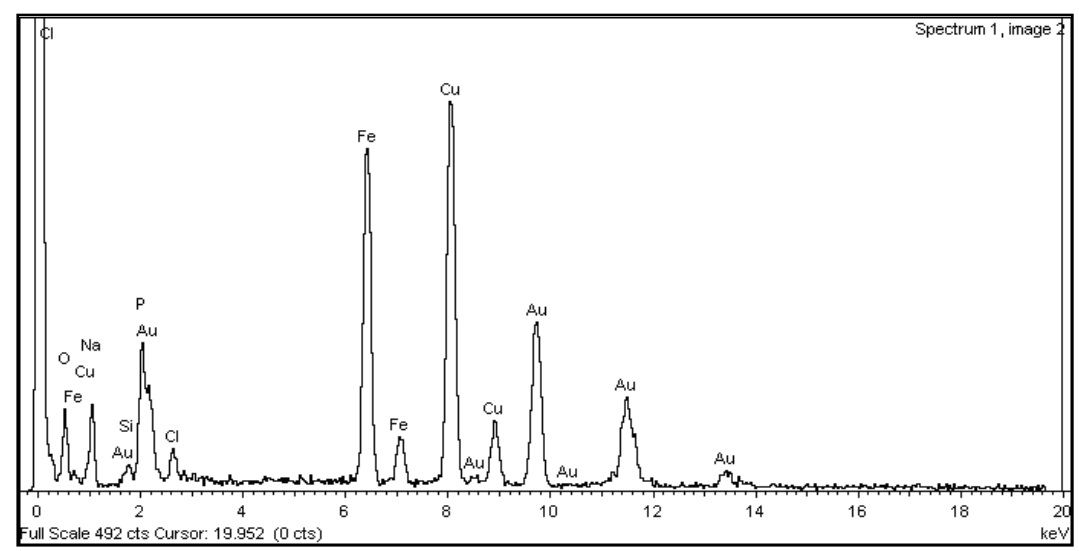

EDX analysis of metastable Fe/Au nanoparticles.

\section{Supplementary Materials 2 (S2)}

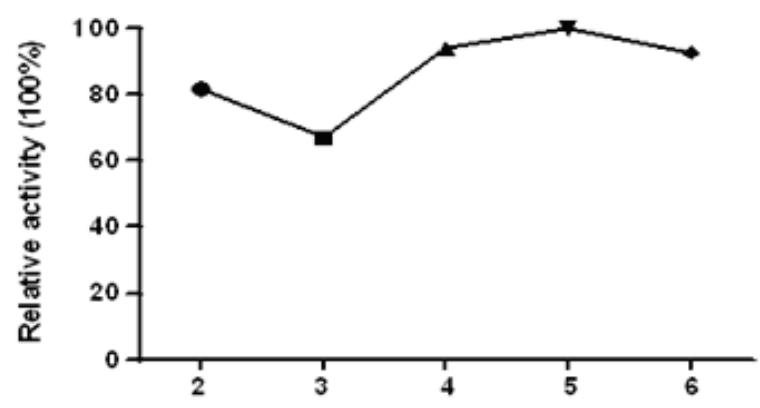

(a) $\mathrm{pH}$ values

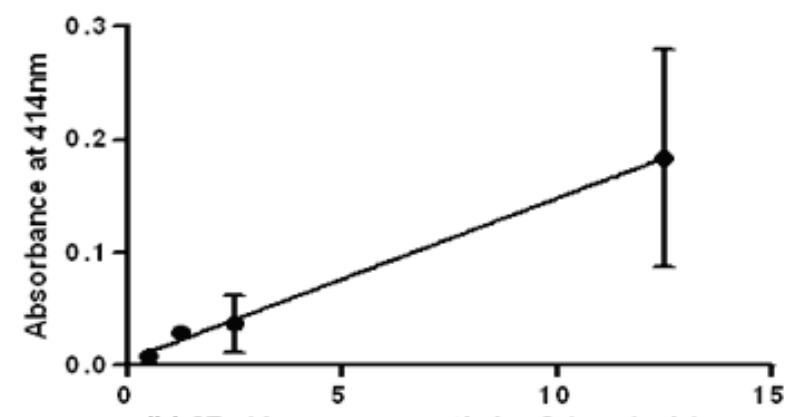

(b) [Fe/Au nanoparticles] ( $\mathrm{mg} / \mathrm{mL})$

a) Effect of different $\mathrm{pH}$ value on $\mathrm{Fe} / \mathrm{Au}$ peroxidase-like activity.

b) Effect of different concentration of $\mathrm{Fe} / \mathrm{Au}$ on peroxidase-like activity (error bars represent S.D. of the absorbance mean). 


\section{Supplementary Materials 3 (S3)}

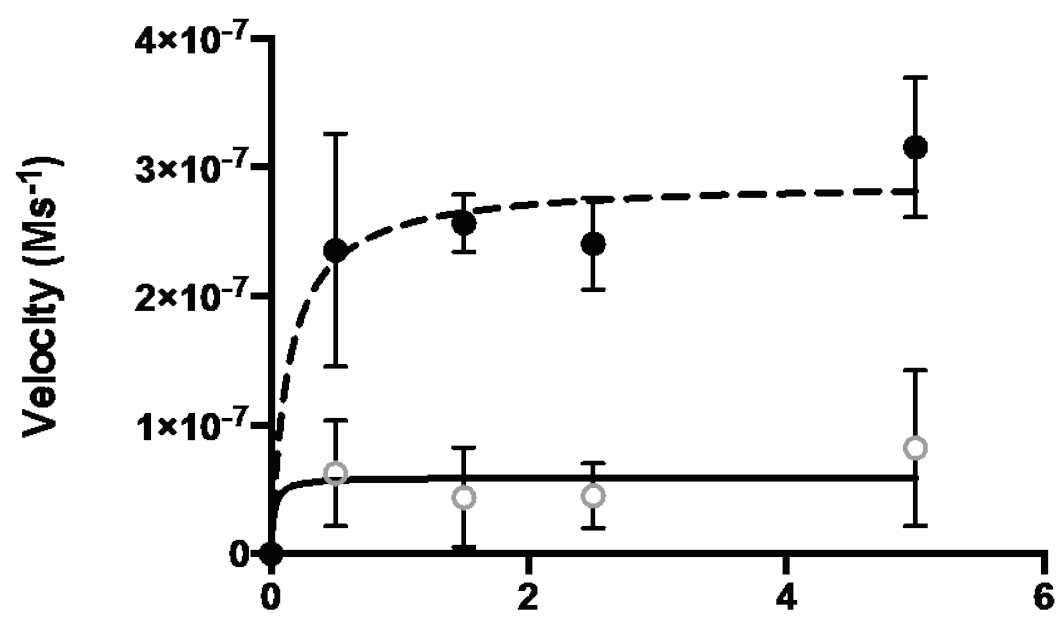

(a) $\mathrm{C}_{\mathrm{HRO} 2}$ (mM)

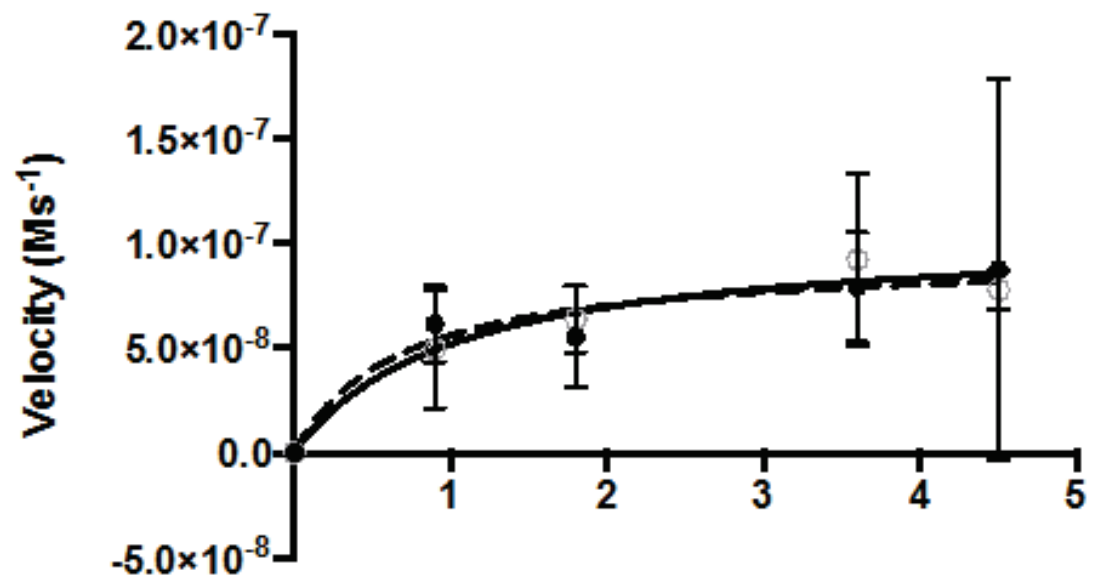

(b) $\mathrm{C}_{\mathrm{ABTS}}(\mathrm{mM})$

Steady-state kinetics of $\gamma$ - $\mathrm{Fe}_{2} \mathrm{O}_{3}$ (dashed line) and $\mathrm{Fe}$-Au nanoparticles (black line) with (a) ABTS concentration at $1.8 \mathrm{mM}$ and varied $\mathrm{H}_{2} \mathrm{O}_{2}$ concentration and (b) $\mathrm{H}_{2} \mathrm{O}_{2}$ concentration at $5 \mathrm{mM}$ and varied ABTS concentration (error bars represent S.D. of the velocity mean). 
Supplementary Materials 4 (S4)

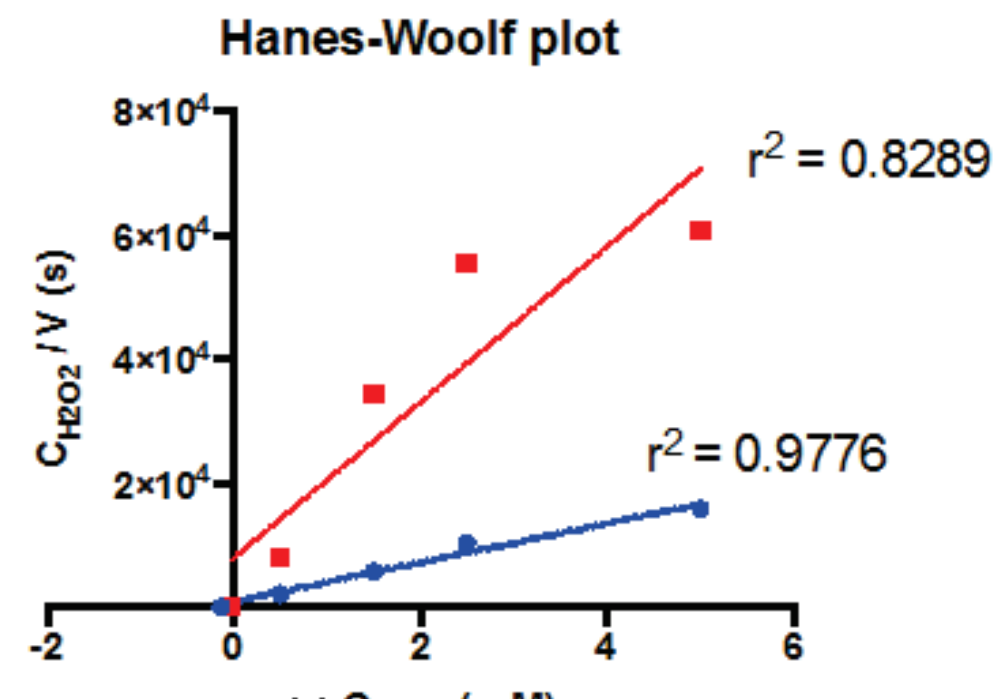

(a) $\mathrm{C}_{\mathrm{H} 2 \mathrm{O} 2}(\mathrm{~m} \mathrm{M})$

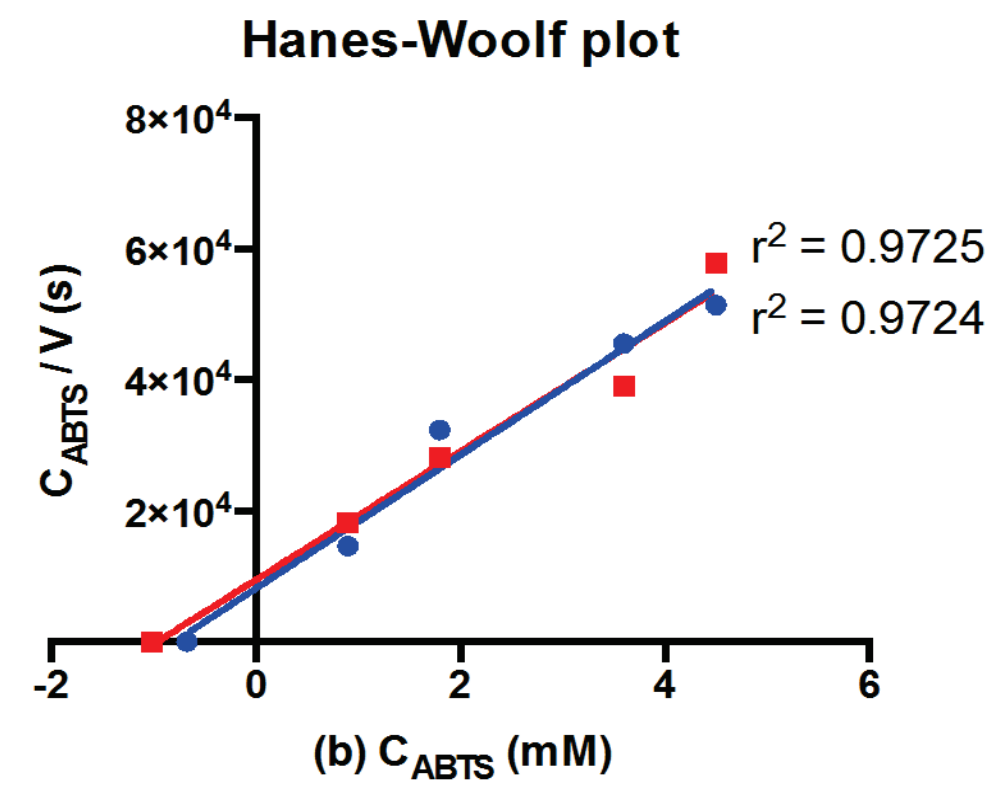

Hanes-Woolf plot of $\gamma-\mathrm{Fe}_{2} \mathrm{O}_{3}$ (blue) and $\mathrm{Fe} / \mathrm{Au}$ nanoparticles (red) (a) with ABTS concentration at $1.8 \mathrm{mM}$ and varied $\mathrm{H}_{2} \mathrm{O}_{2}$ concentration and (b) with $\mathrm{H}_{2} \mathrm{O}_{2}$ concentration at $5 \mathrm{mM}$ and varied $\mathrm{ABTS}$ concentration. 


\section{Supplementary Materials 5 (S5)}

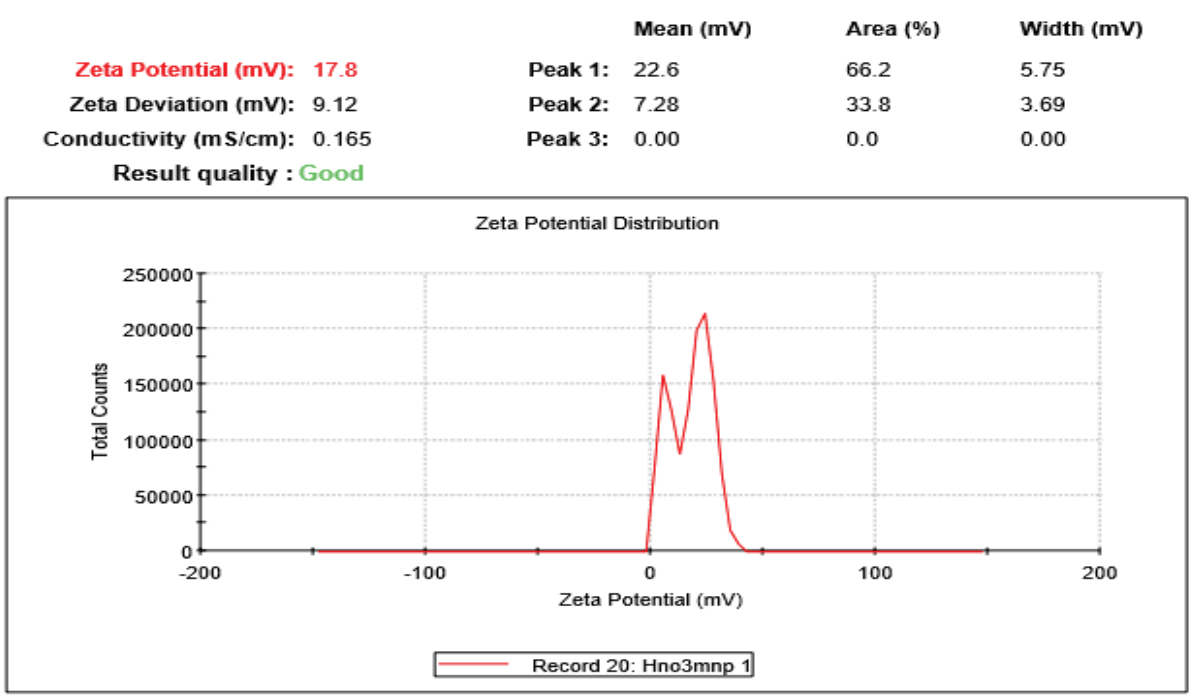

DLS measurement of $\gamma$-Fe2O3 surface charge.

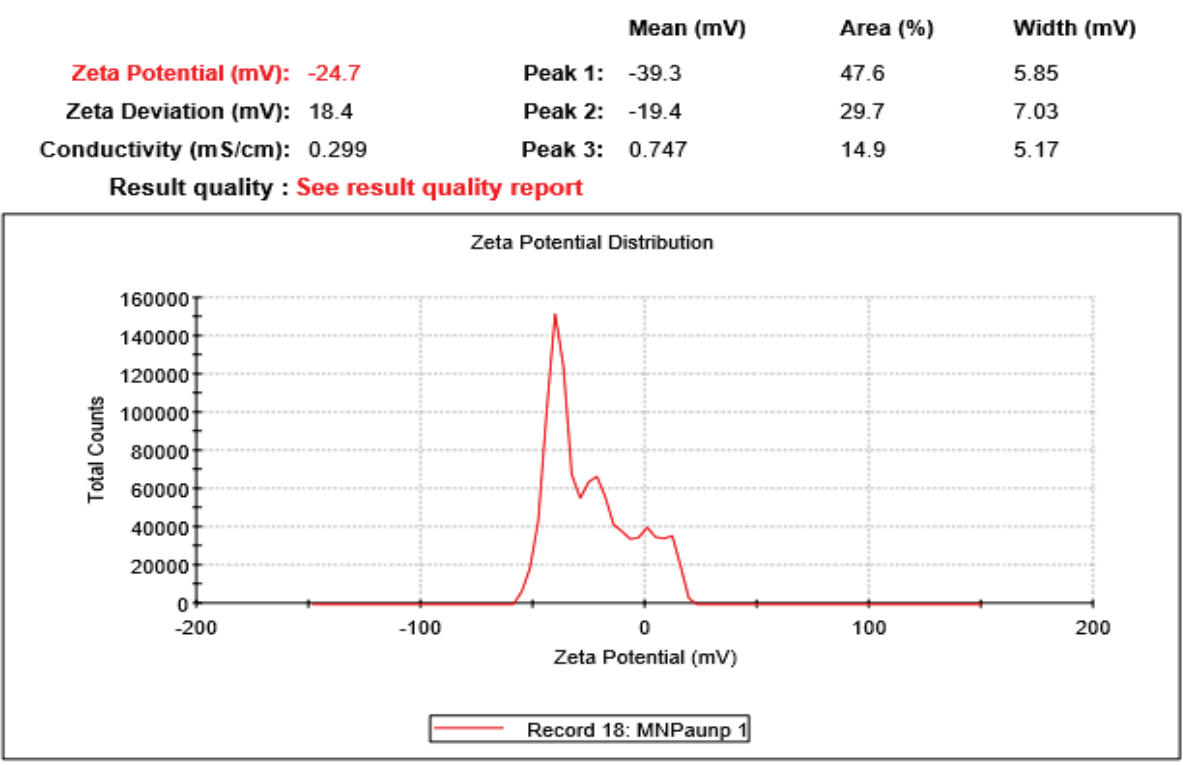

DLS measurement of $\mathrm{Fe} / \mathrm{Au}$ nanoparticles surface charge. 


\section{Supplementary Materials 6 (S6)}

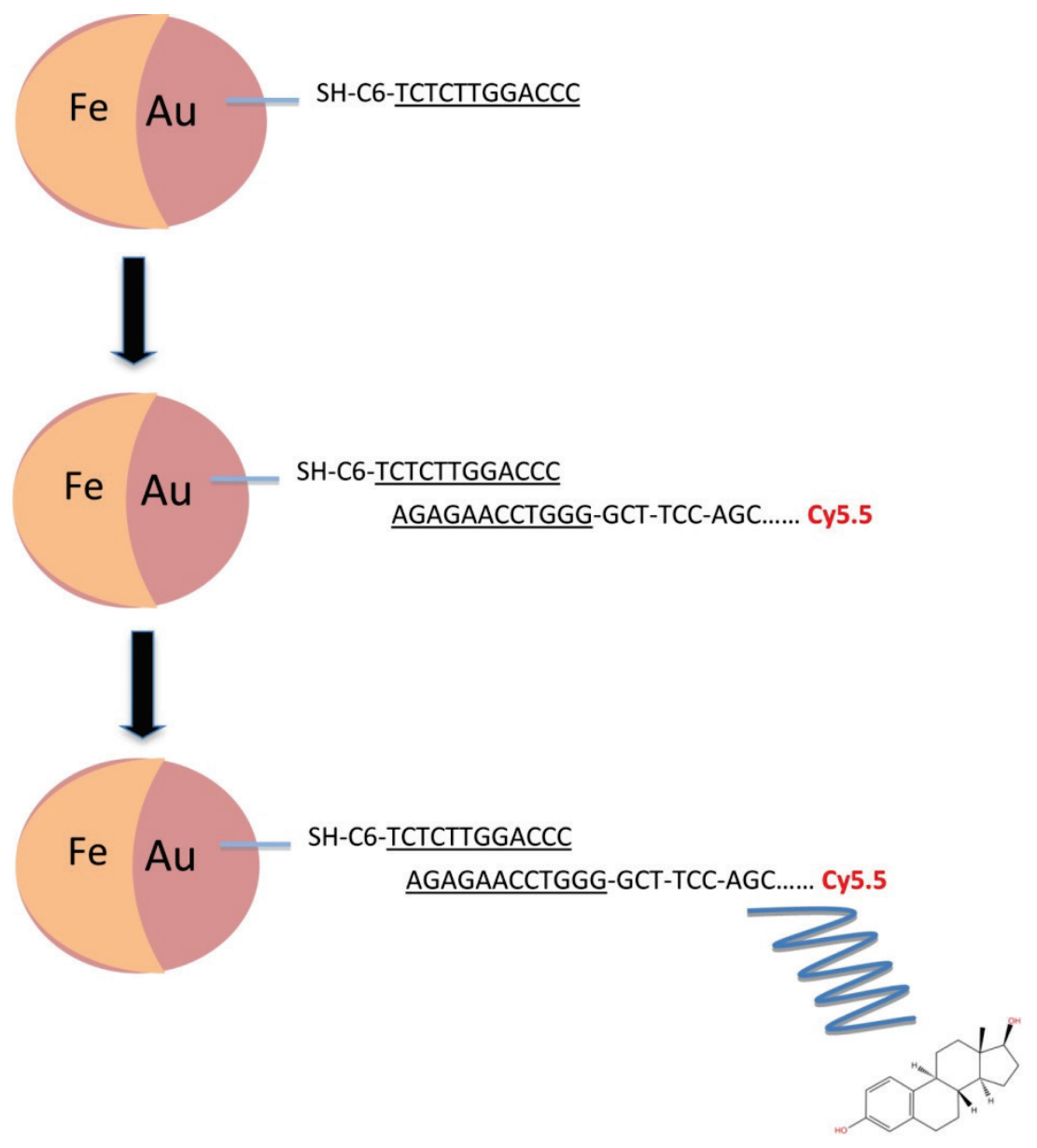

A sequential attachment of thiolated aptamer (SH-apt) and probe aptamer (fl-apt) to functionalise $\mathrm{Fe} / \mathrm{Au}$ nanoparticle surfaces followed by conjugation of $17 \beta$-estradiol at the site-specific sequence to generate $\mathrm{Fe} / \mathrm{Au}-17 \beta$-estradiol complex. 


\section{Supplementary Materials 7 (S7)}

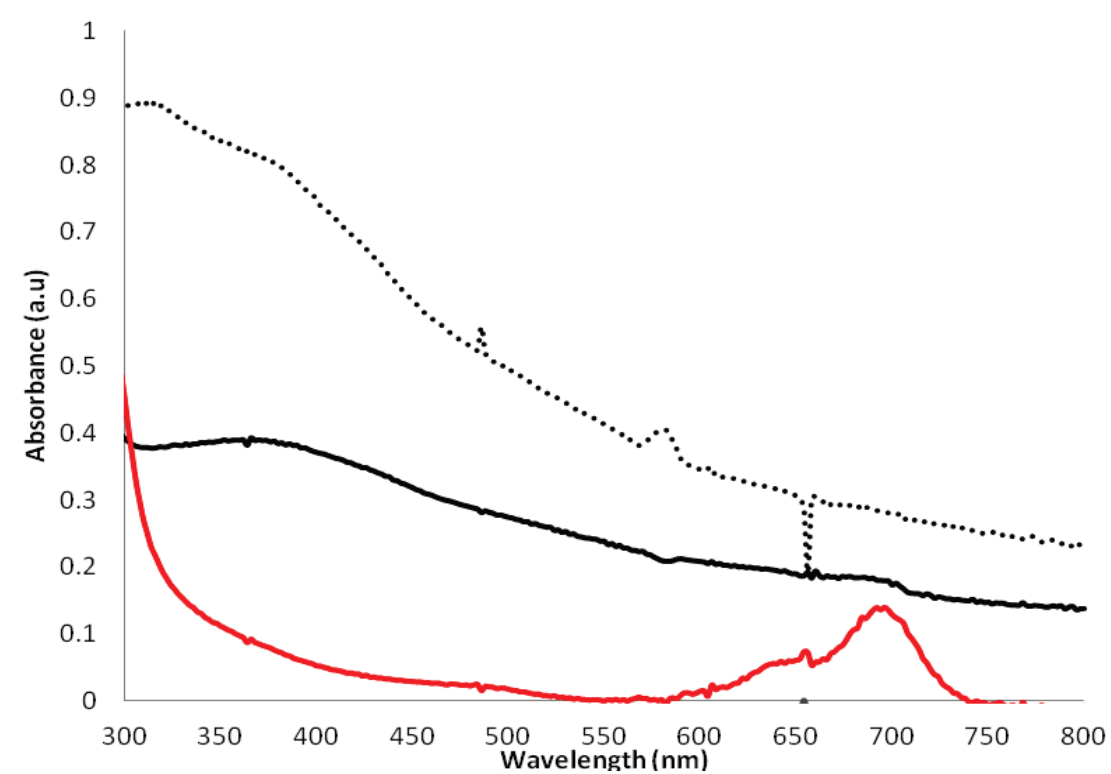

UV-Vis spectrophotometer measurement of Fe/Au nanoparticles (black dots), Fe/Au-flapt (solid black) and probe aptamer, fl-apt as a sample control (solid red).

\section{Supplementary Materials 8 (S8)}

Intra-assay coefficients of variation $(\mathrm{CV})$ for serial dilutions of $17 \beta$-estradiol at 2.5 $\mathrm{mg} / \mathrm{mL}$ of aptamer-tagged nanoparticles for batch-to-batch reproducibility determination.

\begin{tabular}{cccc}
\hline$[17 \beta$-estradiol $](\mathrm{nM})$ & Mean $(\mathrm{n}=2)$ & S.D. & CV $(\%)$ \\
\hline 0.01 & 0.047 & 0.003 & 7 \\
0.10 & 0.029 & 0.008 & 26 \\
1 & 0.018 & 0.001 & 4 \\
10 & 0.012 & 0.009 & 77 \\
\hline
\end{tabular}

